\title{
IMPACTO DA DIVULGAÇÃO OBRIGATÓRIA DA DVA: EVIDÊNCIA EM INDICADORES FINANCEIROS ${ }^{1}$
}

\author{
IMPACT OF MANDATORY DISCLOSURE OF VAS: \\ EVIDENCE ON FINANCIAL INDICATORS
}

\author{
Ismael Alencar Fiuza de Oliveira ${ }^{2}$ \\ Graduado em Ciências Contábeis \\ Universidade Federal do Ceará (UFC) \\ ismael fiuza@hotmail.com \\ Antônio Carlos Dias Coelho \\ Doutor em Controladoria e Contabilidade pela USP \\ Bolsista de Produtividade em Pesquisa do CNPq \\ Professor do Programa de Pós-Graduação em Administração e Controladoria da UFC \\ accoelho47@gmail.com
}

\begin{abstract}
RESUMO
No contexto da discussão sobre a evidenciação de informações contábeis de ser tratada de forma voluntária ou obrigatória, um dos argumentos favoráveis à obrigatoriedade consiste no caráter menos verificável da informação voluntária, em razão de não ser submetida a procedimentos de confirmação mais rigorosos, estando sujeita a vieses e a depender do julgamento de seus investidores. De outra parte, argumentos contrariam tal visão, no sentido de que incentivos econômicos e informacionais seriam suficientes para divulgar informações contábeis de forma eficiente. Neste sentido, a pesquisa investigou em que medida a obrigatoriedade de divulgação da DVA, instituída pela Lei $\mathrm{n}^{\mathrm{o}} 11.638 / 07$, pode ter impactado a propriedade informacional de indicadores financeiros de análise da geração e da distribuição do valor adicionado. A amostra da pesquisa foi composta por 81 companhias listadas na BM\&FBOVESPA, que divulgavam a DVA voluntariamente antes do advento da nova legislação contábil. O estudo envolveu os períodos de 2005 a 2007, antes da obrigatoriedade, e 2008 a 2012, após a obrigatoriedade de divulgação. Os dados foram obtidos no sítio da BM\&FBOVESPA e foram submetidos a testes paramétricos e não paramétricos de diferença entre médias e a análise por regressão logística. Os resultados apontaram haver mudanças estatisticamente significantes em apenas dois dos indicadores analisados que relacionam geração de valor adicionado e receita e que mostram a parcela do valor adicionado destinada a acionistas. Podese inferir, assim, que o processo regulatório adotado na contabilidade brasileira não afetou de forma generalizada os números divulgados pela DVA.
\end{abstract}

Palavras-chave: Evidenciação Contábil Obrigatória. Qualidade Informacional. Demonstração do Valor Adicionado.

\footnotetext{
${ }^{1}$ Artigo recebido em: 23/10/2014. Revisado por pares em: 23/11/2014. Recomendado para publicação em: 26/11/2014 por Orleans Silva Martins (Editor Geral). Publicado em: 28/11/2014. Organização responsável pelo periódico: UFPB.

2 Endereço: Rua 65, 140, Prefeito José Walter, CEP 60750-790, Fortaleza/CE.

DOI: http://dx.doi.org/10.18405/recfin20140303
} 


\section{ABSTRACT}

In the context of discussion about the financial disclosure to be treated on a voluntary or mandatory basis, one of the arguments in favor of mandatory is the less verifiable character of voluntary information, because it is not subject to more rigorous confirmation procedures, thus being exposed to biases and depending on the investors' judgment. On the other hand, arguments contradict such a view, in the sense that economic and informational incentives would be sufficient to disclose accounting information efficiently. Thus, the research investigated to what extent mandatory disclosure of VAS, established by Law $\mathrm{n}^{\mathrm{o}}$ 11.638/07, may have impacted on the informational property of financial indicators for analysis of value added formation and distribution. The research sample was composed by 81 companies listed at the BM\&FBOVESPA that disclosed VAS voluntarily before the advent of the new accounting legislation. The study involved the periods 2005-2007, before the requirement, and 2008-2012, after it. The data were obtained on the BM\&FBOVESPA website and have been submitted to parametric and nonparametric tests of differences between means and logistic regression analysis. The results showed a statistically significant change in only two of the examined indicators, that relate value added creation and revenue and show the portion of value added allocated to shareholders. Therefore we can infer that the regulatory process adopted in the Brazilian accounting does not generally affect the data released by VAS.

Keywords: Mandatory Disclosure. Information Quality. Value Added Statement.

\section{CONTEXTUALIZAÇÃO}

Os padrões contábeis brasileiros mudaram em convergência ao padrão contábil internacional. A Lei n⿳0 11.638/07 determinou a harmonização contábil no Brasil ao IFRS e alterou os dispositivos da Lei no 6.404/76 que impediam a adoção das práticas internacionais de contabilidade (IUDÍCIBUS et al., 2010). No conjunto das alterações instituídas pela Lei $\mathrm{n}^{\mathrm{o}} 11.638 / 07$, a despeito de não ser relatório referenciado pelo International Accounting Standard Boards (IASB), incluiu-se no rol de demonstrações contábeis obrigatórias a serem elaboradas e divulgadas pelas companhias abertas a Demonstração do Valor Adicionado (DVA), que até o ano de 2007 consistia em informação contábil voluntária.

Segundo Tinoco (2009), a divulgação voluntária da DVA sujeitava-se frequentemente a vieses em razão de ser feita fora do Sistema de Informações Contábeis das empresas, não ser objeto de auditoria ou de outros procedimentos de confirmação e de ser evidenciada de acordo com o enfoque particular de quem a elaborava por falta de regras definidas quanto a conteúdo e classificação. Tais características coadunam com o raciocínio de que divulgações voluntárias, em muitos casos, não são verificáveis e dependem, pois, de julgamentos e crenças dos administradores, tendo sua veracidade avaliada após a publicação dos relatórios financeiros obrigatórios (YAMAMOTO; SALOTTI, 2006), o que poderia redundar em informações com pouca utilidade para seus usuários.

Entretanto, de acordo com Santos (2007), a elaboração da DVA normalmente tem como base dados extraídos de outras demonstrações contábeis, principalmente da Demonstração de Resultados do Exercício, as quais são submetidas à auditoria externa, o que presumivelmente tornaria aquela demonstração menos sujeita a distorções, tendo em vista o efeito esperado de diminuição de ações discricionárias dos administradores (PAULO, 2007).

Além disso, tanto a Comissão de Valores Mobiliários (CVM), através do Ofício-Circular CVM/SNC/SEP no 1/00, quanto o Conselho Federal de Contabilidade (CFC), por meio da Resolução CFC n⿳0 1.010/05, apresentaram modelos e procedimentos para a evidenciação voluntária da DVA que muito se assemelham, inclusive, àqueles definidos pelo Pronunciamento Técnico CPC 09 - Demonstração do Valor Adicionado, cuja observância se tornou obrigatória para as companhias abertas através da Deliberação CVM no 557/08. 
Vale ressaltar que tanto o Ofício-Circular CVM/SNC/SEP no 1/00 quanto a Resolução CFC n⿳⺈ 1.010/05 apresentam modelos de evidenciação genéricos que permitem discricionariedades para adaptar a demonstração à atividade econômica da entidade, embora o modelo CFC seja mais detalhado e suas orientações de elaboração mais especificadas e elucidativas, quando comparado ao modelo CVM.

De outra parte, o CPC 09 apresenta modelos específicos e detalhados para empresas comerciais e industriais, para instituições financeiras e para entidades de seguro e previdência, reduzindo o grau de discricionariedade na elaboração, pois os três modelos são acompanhados por orientações próprias de elaboração. Ou seja, o modelo de evidenciação da DVA é basicamente o mesmo para os três casos, exceto pela variação do grau de detalhamento dos seus componentes e pela maior ou menor especificação de seus procedimentos de elaboração, não havendo incoerência ou oposição entre tais casos.

Neste contexto, ainda, progredia o número de empresas que divulgavam a DVA, conforme Cunha, Ribeiro e Santos (2005) motivadas por razões como a admissão de responsabilidade social, as cobranças da sociedade (estímulo advindo de associações de trabalhadores), ou ainda, como forma de marketing. Tais autores ainda relacionam essas razões de se evidenciar a DVA para a regulação prevista no novo texto legal.

Quanto ao debate acerca de como proceder com o disclosure, se de forma voluntária ou obrigatória, argumenta-se, a favor da obrigatoriedade, a insuficiência da informação divulgada aos usuários, em razão do julgamento das empresas de que poderiam favorecer concorrentes ao divulgarem certa informação (YAMAMOTO; SALOTTI, 2006), cenário em que a regulação funcionaria como mecanismo de comprometimento, exigindo a evidenciação de informações de que os usuários necessitam, mas que as firmas não estão dispostas a divulgar (MURCIA, 2010).

Esses argumentos estão fundamentados na possível incapacidade do mercado de disciplinar adequadamente o processo de evidenciação pública de informações sem penalizar agentes menos favorecidos (LOPES, 2002). A regulação deriva, pois, da existência de assimetria da informação, e busca proteger investidores menores e beneficiar a maior parte do mercado, obrigando a divulgação de informações padronizadas e comparáveis (MURCIA, 2010).

No que tange aos efeitos da regulação, Sarlo Neto, Lopes e Loss (2002) afirmam que a regulação existente, independentemente do grau de especificidade terá efeito sobre o processo de elaboração e divulgação das informações contábeis, podendo, pois, distorcer a capacidade informacional da contabilidade. Neste sentido, alguns estudos dedicaram-se a observar os efeitos de processos regulatórios, por exemplo, sobre o nível de conservadorismo contábil das empresas (COSTA et al., 2009; KAIZER et al., 2009); sobre o preço das ações (BARBOSA; DIAS; MÁRIO, 2011); sobre o impacto no valor da firma (POPOVA et al., 2013) e acerca do comportamento de risk-averse insider (HUANG, 2007).

A DVA se insere nesse contexto de discussão, haja vista que seu processo de regulação implicou na obrigatoriedade de aplicação de princípios de elaboração e divulgação uniformes e comparáveis para companhias de capital aberto sujeitas à aplicação do Pronunciamento Técnico CPC 09 (Deliberação CVM no 557, 2008). Diante do exposto, questiona-se se o estabelecimento da obrigatoriedade da publicação da DVA, além do estabelecimento de princípios para sua elaboração, o que implicaria em maior rigor nos processos de elaboração e divulgação, impactaram os dados reportados nas Demonstrações do Valor Adicionado.

Método pertinente para avaliar tal possibilidade é o estudo do comportamento dos indicadores financeiros destinados à avaliação financeira das firmas, recentemente usado em pesquisas interessadas em constatar o impacto da adoção do padrão IFRS (CARVALHO et al., 2011; MARTINS; PAULO, 2010; BARBOSA; DIAS; PINHEIRO, 2009). Deste modo, podem-se selecionar indicadores financeiros derivados da DVA e examinar seu comportamento ao longo de série temporal 
dos mesmos. Destarte, formula-se a seguinte questão para a pesquisa: qual é o impacto da determinação da obrigatoriedade de divulgação da DVA, instituída pela Lei $n^{\underline{0}} 11.638 / 07$, sobre os indicadores financeiros emanados da DVA de empresas brasileiras?

Considerando que os procedimentos que orientavam a elaboração e divulgação da DVA antes de determinada a sua obrigatoriedade (CVM, 2000; CFC, 2005) são semelhantes aos estabelecidos para sua divulgação obrigatória (CVM, 2008); que a DVA, ainda que voluntária e teoricamente menos verificável, era elaborada a partir de dados auditados extraído de outras demonstrações contábeis, formula-se a seguinte hipótese:

$\mathrm{H}_{0}$ : Não houve impactos estatisticamente significantes nos indicadores emanados da DVA obrigatória ante os indicadores emanados da DVA voluntária.

Para o caso de constatação de impactos, a explicação das diferenças poderia residir na mudança de tratamento de divulgação, em virtude da alteração dos fatores que envolvem a elaboração e divulgação da informação quando tratada de forma voluntária para quando tratada de forma obrigatória, tais como motivações internas, financeiras ou não, da firma para divulgar ou reter a informação, a percepção dos gestores e a crença dos usuários da informação sobre a entidade, o nível de discricionariedade ou leque de escolhas contábeis (VERRECCHIA, 2001; LOPES; TUKAMOTO, 2007; PAULO, 2007). Destarte, o objetivo da pesquisa consiste em avaliar os possíveis impactos da determinação da obrigatoriedade da DVA na qualidade dos indicadores financeiros oriundos das demonstrações assim preparadas.

A pesquisa teve por base DVA publicadas por companhias de capital aberto nos anos de 2005 a 2007, período anterior à regulamentação - divulgação voluntária - e nos anos de 2008 a 2012, período posterior à normatização da obrigatoriedade. Assim, vê-se relevante oportunidade para avaliar se o processo de regulamentação (obrigatoriedade) altera a qualidade da informação contábil levada a público; especificamente se examina tal situação na DVA brasileira, já que a alteração de padrão contábil no país propicia a efetivação de testes neste sentido.

\section{SUPORTE TEÓRICO}

\subsection{O Valor Adicionado e a DVA}

Cunha (2002, p. 33), de maneira direta, define valor adicionado pela assertiva seguinte: "quanto às atividades produtivas agregam de valor aos insumos adquiridos". O conceito de valor adicionado é discutido de maneira diversa sob dois enfoques: macro e microeconômico. Quanto ao aspecto macroeconômico, o valor adicionado está associado à apuração do produto nacional, ao passo que, do ponto de vista microeconômico, é o montante de riqueza que a firma pode agregar, em seu processo produtivo, aos insumos que foram adquiridos por terceiros (SANTOS 2007).

O cálculo do valor adicionado poderá ser feito sob os pontos de vista econômico, que se baseia na produção - o valor adicionado seria o resultado da diferença entre a produção bruta num dado período e os insumos consumidos nessa produção - e contábil, orientado a partir das receitas de venda. Infere-se, pois, que entre os dois conceitos há uma diferença temporal (IUDÍCIBUS et al., 2010), haja vista que o modelo econômico reconhece a geração de valor agregado, independentemente da realização financeira dos estoques.

Com base na visão contábil, De Luca (1992, p. 56) explica que o valor adicionado “[...] é obtido, de forma geral, pela diferença entre as vendas e o total dos insumos adquiridos de terceiros. Este valor será igual à soma de toda a remuneração dos esforços consumidos nas atividades da empresa". Conforme Cosenza (2003), o valor adicionado apurado com base nas receitas de venda possibilita tanto a avaliação do desempenho dos gestores em gerar valor para a entidade, como o 
estabelecimento de relações entre este valor e o padrão contábil em que se embasa a elaboração das demonstrações contábeis tradicionais.

A demonstração contábil que evidencia o cálculo de obtenção do valor adicionado, bem como sua distribuição entre os elementos que contribuíram com a sua geração (empregados, governo e demais capitalistas) é a Demonstração do Valor Adicionado. A DVA, conforme Cunha, Ribeiro e Santos (2005), é um demonstrativo contábil que apresenta os benefícios trazidos pela entidade à comunidade em que está inserida - através, por exemplo, da absorção de sua mão de obra -, e o potencial de geração de riqueza contributiva ao desenvolvimento econômico.

Os autores também apontam que a DVA possibilita a identificação da riqueza recebida em transferência e apresenta "um mapeamento de como essas riquezas são distribuídas aos seus diversos beneficiários: empregados, governo, financiadores externos e sócios ou acionistas" (CUNHA; RIBEIRO; SANTOS, 2005, p. 9).

A DVA é instrumento contábil de genuína importância, pois contém informações que permitem avaliar o desempenho econômico e a capacidade de geração de riqueza da firma, bem como a forma com que se remuneram os fatores de produção (trabalhadores e financiadores), auxiliar o cálculo do PIB e de indicadores sociais, fornecer informações sobre a contribuição da empresa com o desenvolvimento econômico da região em que se instala (IUDÍCIBUS et al., 2010).

Santos (2007, p. 39) ressalta a importância dos efeitos da divulgação da DVA, justificada na possibilidade de análise "que de forma alguma poderia ser alcançada apenas com as demonstrações contábeis tradicionais que a Contabilidade oferece". Confirmando tal ideia, Crippa e Coelho (2012) concluíram que a DVA provê informações que podem ser úteis à redução da assimetria informacional, tendo em vista que os resultados de sua pesquisa apontaram correlação estatisticamente significante entre o Valor Adicionado Total a Distribuir, evidenciado na DVA, e o retorno das ações, podendo, pois, subsidiar decisões de investimentos.

Por fim, Muñoz (1989 apud COSENZA, 2003, p. 20) conclui,

\footnotetext{
Por suposto, fica claro que a DVA pode ser utilizada como uma ferramenta básica na análise patrimonial, econômica e financeira, constituindo-se em um importante complemento do lucro contábil, ao manifestar diferentes magnitudes econômicas e sociais que estão relacionadas na atividade da empresa.
}

Em razão do exposto, é possível cogitar que a transparência quanto à responsabilidade social das empresas, a necessidade ou exigência informacional de usuários - ressaltam-se aqueles não atendidos satisfatoriamente com as informações reportadas nas demonstrações contábeis tradicionais -, a relevância da informação gerada pela DVA, ou, ainda, a publicidade de que fora alvo são fatores que podem explicar os atos, tanto de divulgar voluntariamente a DVA, como de tornála obrigatória para as companhias abertas, tal como foi estabelecido pela Lei ํำ 11.638/07.

\subsection{Teoria da Divulgação Voluntária}

Cunha e Ribeiro (2006, p. 4) definem a Teoria da Divulgação como "uma linha de pesquisa que tem por objetivo explicar o fenômeno da divulgação de informações financeiras". Fundamentalmente, os estudos que tratam sobre as conjunturas ou fatores relacionados à comunicação formal de informações produzidas pela contabilidade estão intimamente envolvidos com este conceito. Verrecchia (2001) propõe três categorias que envolvem as pesquisas sobre divulgação, para as quais propõe modelos analíticos: (1) divulgação baseada em associação, que estuda os efeitos da divulgação no comportamento de investidores; (2) divulgação baseada em julgamento, que busca identificar as razões internas à empresa que orientaram a decisão de divulgar a informação; e, (3) divulgação baseada em eficiência, que, na ausência de conhecimento anterior sobre a informação, que conjunto de informações é preferido ou mais eficiente. 
A categoria de divulgação baseada em julgamento é também conhecida por Teoria da Divulgação Voluntária (YAMAMOTO; SALOTTI, 2006) que, com o objetivo de identificar o conjunto de circunstâncias que levam gestores a divulgar voluntariamente ou reter determinada informação, tem motivado pesquisadores a elaborar modelos analíticos, fundados em premissas econômicas, com a finalidade de relacionar a divulgação contábil às suas consequências, pois que com motivação econômica o estudo do disclosure não fica restrito a opiniões, propiciando o desenvolvimento de seu arcabouço teórico (MURCIA; SANTOS, 2009).

Sobre o modelo analítico proposto por Verrecchia para disclosure discricionário (2001), Alencar (2007, p. 18) emenda,

[...] resulta em cinco hipóteses empiricamente testáveis. Segundo o modelo de Verrecchia, o nível de disclosure tem correlação: (1) Positiva com o desempenho da empresa, (2) Negativa com os custos de divulgação, (3) Positiva com o nível de assimetria informacional entre os investidores externos e a empresa, (4) Positiva com a importância dada pela firma às percepções dos outsiders, e (5) Positiva com o nível passado de divulgação.

Para Dye (2001), a teoria da divulgação voluntária é um caso especial da teoria dos jogos, cuja ideia central reside no ato de divulgar informações favoráveis à empresa e de não divulgar aquela que lhe for desfavorável. Outro raciocínio é o de que só ocorrerá disclosure se os benefícios gerados pela divulgação voluntária, como redução do custo de capital e aumento da liquidez das ações, superarem, por exemplo, os custos de elaboração e publicação da informação ou os custos de propriedade (MURCIA; SANTOS, 2009). Isto é, decide-se divulgar voluntariamente uma informação quando os benefícios superam os custos em que incorrem gestores e a própria empresa.

Daí se percebe que a divulgação voluntária de informações é, antes de tudo, uma responsabilidade dos gestores (POPOVA et al., 2013) e consiste, dada a concorrência entre elementos que justificariam a retenção ou liberação da informação, em decisão de significativa importância (CONSONI, 2014). Não é de qualquer forma, portanto, que a administração de uma empresa se decide por divulgar uma informação, mas sim definindo cuidadosamente estratégias de divulgação que lhe permita obter benefícios tais como maior liquidez de suas ações e melhor reputação da companhia no mercado (ENTWISTLE, 1997).

Neste mesmo sentido, considera-se que, na divulgação voluntária há mensagens implícitas que reforçam pontos positivos e omitem pontos negativos ou limitadores acerta do desempenho dos gestores (COLAUTO; MARQUES, 2010), os quais, ao se decidirem por qual informação divulgar, avaliam de que forma os métodos de mensuração e evidenciação afetam sua riqueza, podendo direcionar suas escolhas por incentivos econômicos (WATTS; ZIMMERMAN, 1986 apud CONSONI, 2014).

Destarte, vê-se que a administração estará propensa a divulgar informações conforme seus interesses, buscando alternativas que lhe permita obter o efeito almejado decorrente da divulgação. Essas alternativas deverão estar disponíveis conforme a amplitude de discricionariedade consentida pelas normas e práticas permitidas pelos órgãos reguladores (PAULO, 2007). Isso porque a companhia deve buscar mecanismos que creditem confiabilidade às informações divulgadas voluntariamente, pois, se não o fizer, tais informações poderão ter pouco significado (CONSONI, 2014), haja vista que, conforme Yamamoto e Salotti (2006), divulgações voluntárias tendem a ser menos verificáveis que divulgações obrigatórias.

Consoante a isso, observa-se que a credibilidade da informação no mercado de capitais é positivamente influenciada pela existência de regulação sobre sua divulgação (POPOVA et al., 2013). Ainda nesse contexto, espera-se que o conjunto de normas restrinja a possibilidade do emprego de manipulação de informações, que ocorrem em função de imperfeições do mercado e se originam de desejos de teor fundamentalmente econômico (PAULO, 2007). Vale ressaltar que, no 
momento em que agentes reguladores determinam a obrigatoriedade de se divulgar certa informação que até então não era obrigatória, não haverá mais necessidade da companhia criar estratégias de divulgação voluntária (EINHORN, 2005 apud POPOVA et al., 2013).

Logo, é possível observar a intensidade com que a divulgação voluntária é alvo de escolhas contábeis, cuja decisão envolve diversos fatores, sobretudo internos à companhia e relacionados aos interesses econômicos tanto dos gestores quanto da firma; e a maneira com que processos regulatórios reduzem a influência desses fatores no ambiente de elaboração e evidenciação de informações contábeis.

Dentre os trabalhos que se utilizaram do arcabouço da Teoria da Divulgação, pode ser citado o estudo de Yamamoto (2005 apud YAMAMOTO; SALOTTI, 2006), que constatou correlação positiva entre o nível de divulgação de informações voluntárias no mercado de capitais brasileiro com a qualidade da divulgação, verificada quando impacta positivamente no valor das ações. Como parte dos resultados de tal estudo, a DVA, dentre outras informações, é considerada divulgação de qualidade, pois contribui para reduzir a volatilidade do retorno.

O estudo de Salotti e Yamamoto (2008), inserido no campo de pesquisas sobre divulgação baseada em julgamento, identificou razões de se evidenciar voluntariamente a Demonstração de Fluxos de Caixa (DFC) no mercado de capitais brasileiro, com base no modelo proposto por Verrecchia (2001), tais como o fato de a companhia já ter divulgado a DFC anteriormente ou importarse com a percepção de outsiders; também por apresentar melhor desempenho e menores custos de divulgação, e por intenção de reduzir assimetria informacional.

O estudo de Cunha e Ribeiro (2006) buscou identificar evidências sobre os motivos que levariam companhias abertas a divulgarem voluntariamente informações de natureza social. Os resultados obtidos mostraram que a divulgação voluntária de informações de cunho social está associada positivamente apenas ao nível passado da divulgação nos dois períodos e aos níveis de governança em 2004.

\section{PROCEDIMENTOS METODOLÓGICOS}

A população objeto de estudo compreendeu as companhias de capital aberto listadas na BM\&FBOVESPA que divulgaram voluntariamente a DVA antes de 2008. A coleta de dados foi procedida no banco de dados do sítio da BM\&FBOVESPA, especificamente nos formulários das Demonstrações Financeiras Anuais Completas. Para o cálculo dos indicadores financeiros foram utilizadas as informações contidas nas DVA e nos balanços patrimoniais, envolvendo os períodos de 2005 a 2007 - antes da regulação - e 2008 a 2012 - após a regulação. Exercícios anteriores a 2005 não foram utilizados por conta da redução considerável do número de empresas que divulgaram a DVA antes deste ano.

A amostra, intencional e censitária pelas características do objeto de estudo, abrangeu inicialmente 83 empresas, correspondendo a 664 observações-ano. Entretanto, após a exclusão dos períodos que apresentaram outliers para pelo menos um indicador, dentro de um intervalo de confiança de 5\%, restou composta por 81 empresas que correspondem a 580 observações-ano. Dessas observações, 221 correspondem a divulgações voluntárias da DVA, das quais se buscou identificar características tais como: 1) referência a modelos e procedimentos de elaboração utilizados; 2) informações sobre submissão do relatório ao crivo da auditoria externa; 3) existência de informações sobre possível não conformidade em relação aos modelos de evidenciação propostos pela CVM e pelo CFC; e 4) relatório no qual foram divulgadas as demonstrações sob referência - relatório da administração, notas explicativas etc. - visando, assim, analisar a qualidade dos dados.

Para a seleção dos quocientes a serem examinados, teve-se como critério primordial sua relação de análise com a geração e distribuição de riqueza e sua utilidade para a compreensão das informações contidas na DVA, inclusivamente aqueles cuja obtenção se dá em conjunto com in- 
formações de outras demonstrações contábeis. Os indicadores utilizados foram classificados por tratarem de: a) geração de riqueza; e b) distribuição de riqueza, caracterizados em Iudícibus et al. (2010) e em Santos (2007), consoante referenciados no Quadro 1.

Quadro 1 - Indicadores de análise da DVA a serem utilizadas pela pesquisa.

\begin{tabular}{|c|c|c|}
\hline Grupo & Indicador & Fórmula \\
\hline \multirow{3}{*}{$\begin{array}{l}\text { Indicadores de } \\
\text { geração de } \\
\text { riqueza }\end{array}$} & Quociente entre valor adicionado e ativo total & $V A S A T=\frac{V A D}{A T}$ \\
\hline & Quociente entre valor adicionado e patrimônio líquido & $V A S P L=\frac{V A D}{P L}$ \\
\hline & Quociente entre valor adicionado e receita & $V A S R=\frac{V A D}{R}$ \\
\hline \multirow{5}{*}{$\begin{array}{l}\text { Indicadores de } \\
\text { distribuição de } \\
\text { riqueza }\end{array}$} & Quociente entre gastos com pessoal e valor adicionado & $P S V A=\frac{G P}{V A D}$ \\
\hline & Quociente entre gastos com impostos e valor adicionado & $I S V A=\frac{G I}{V A D}$ \\
\hline & $\begin{array}{c}\text { Quociente entre gastos com remuneração de terceiros e } \\
\text { valor adicionado }\end{array}$ & $R T S V A=\frac{G R T}{V A D}$ \\
\hline & $\begin{array}{l}\text { Quociente entre remuneração de acionistas (dividendos e } \\
\text { juros sobre o capital próprio) e valor adicionado }\end{array}$ & $R A S V A=\frac{D+J C P}{V A D}$ \\
\hline & Quociente entre lucros retidos e valor adicionado & $L R S V A=\frac{L R}{V A D}$ \\
\hline
\end{tabular}

Nota: VAD, Valor Adicionado Total a Distribuir; AT, Ativo Total; PL, Patrimônio Líquido; R, Receita; GP, Gastos com Pessoal; GI, Gastos com Impostos; GRT, Gastos com Remuneração de Capital de Terceiros; D, Dividendos; JCP, Juros sobre Capital Próprio; LR, Lucros Retidos.

Para a efetivação do teste de hipótese, além da aplicação do teste de diferença de médias (t) para amostras independentes e do teste não paramétrico de Mann-Whitney, buscou-se função que permita a associação dos indicadores financeiros (variáveis independentes) ao tratamento de divulgação dado à DVA antes e após o processo de regulação, com a finalidade de verificar se em função dos indicadores é possível classificá-la em voluntária (0) ou obrigatória (1) (variável dependente dicotômica) de forma condizente com a realidade observada.

Para tanto, a capacidade dos indicadores financeiros de classificarem a DVA sem distorções substanciais deve ser avaliada a fim de que seja possível estimar os respectivos coeficientes necessários ao cálculo da probabilidade máxima associada à classificação. Em outras palavras, determinada a função, se os indicadores emanados da DVA obrigatória não forem capazes de classificá-la tal como ela é, não se verificarão indícios de impacto do processo regulatório na informação reportada, aceitando $\mathrm{H}_{0}$, haja vista a impossibilidade de distinção significante entre duas categorias de informação. Caso contrário, se os indicadores forem capazes de estimar a probabilidade de classificação da DVA em um dos dois grupos, rejeita-se a hipótese.

Em vista disso, utilizou-se Regressão Logística para determinar a função exigida pela pesquisa e testar a diferença de comportamento nos dois períodos considerados, por conta de sua capacidade de categorizar elementos envolvidos e mensurar a probabilidade de cada elemento estar contido em uma ou outra categoria; tal situação é representada por variável dependente, dicotômica e qualitativa (CORRAR; PAULO; DIAS FILHO, 2009), no caso representando empresas que di- 
vulgaram a DVA de forma voluntária (antes de sua regulamentação) e obrigatória, na forma da regulamentação concomitante ao novo padrão contábil.

Com base no modelo geral da Regressão Logística, em que o logaritmo natural da razão de chance, a qual representa a comparação entre as probabilidades de classificação em cada um dos dois grupos, é igual à soma dos coeficientes das variáveis independentes (indicadores financeiros), ponderadas pelos coeficientes estimados $\left(b_{0}, b_{1}, b_{2}, \ldots, b_{k}\right)$, tem-se a Equação 1 para a pesquisa.

$$
\ln \left(\frac{\mathrm{P}\left(\mathrm{DVA}_{\mathrm{obg}}\right)}{\mathrm{P}\left(\mathrm{DVA}_{\mathrm{vol}}\right)}\right)=\mathrm{b}_{0}+\mathrm{b}_{1} \mathrm{x}_{1 \mathrm{i}}+\mathrm{b}_{2} \mathrm{x}_{2 \mathrm{i}}+\cdots+\mathrm{b}_{\mathrm{k}} \mathrm{x}_{\mathrm{ki}}
$$

Analisando a consistência e a eficiência do modelo LOGIT, atesta-se que seu percentual de acerto é insatisfatório. Operando com as variáveis, este percentual (64,7\%) aumentou apenas 2,8\% em relação ao acerto de referência $(61,9 \%)$ quando considerado apenas o enquadramento da maioria das observações, ainda sem qualquer uso dos indicadores. Os pseudo $-\mathrm{R}^{2}$ apresentaram valores baixos, seja pela medida de Cox \& Snell $(0,028)$ ou pela mensuração de Nagelkerke $(0,038)$, observando-se assim que os tratamentos de divulgação têm reduzido poder de determinação para diferenciar os indicadores pesquisados.

\section{RESULTADOS}

A Tabela 1 apresenta um resumo dos principais atributos normativos e qualitativos da divulgação voluntária da DVA, identificados a partir da análise das 221 DVA correspondentes ao período anterior ao processo regulatório. Através dela, constatou-se que para 43\% das DVA houve manifestação por parte das companhias de que essas demonstrações foram elaboradas de acordo com critérios propostos por órgãos reguladores. Destas, observou-se que $46 \%$ foram elaboradas na forma da Resolução CFC n⿳0 1.010/05; 18\% segundo o modelo desenvolvido pela FIPECAFI, sugerido pela CVM (CVM, 2000); e 36\% de acordo com os dois modelos. Tais números evidenciam a discricionariedade das empresas em observar ou não princípios de elaboração e divulgação da DVA, no período de divulgação voluntária.

Tabela 1 - Atributos identificados da divulgação voluntária da DVA.

\begin{tabular}{l|c|c}
\hline \multicolumn{1}{c|}{ Atributos normativos e qualitativos } & Quantidade & Percentual \\
\hline Possuem referência a modelos e técnicas de elaboração utilizados & 95 & $43 \%$ \\
Há referência sobre seu submetimento aos procedimentos de auditoria externa & 183 & $83 \%$ \\
Apresentam desconformidade em relação aos modelos propostos pelos órgãos reguladores & 51 & $23 \%$ \\
Divulgadas como informação suplementar junto/apenso às demonstrações obrigatórias & 145 & $66 \%$ \\
Divulgadas em notas explicativas & 33 & $15 \%$ \\
Divulgadas no Relatório da Administração & 41 & $19 \%$ \\
\hline
\end{tabular}

Ainda que para os outros $57 \%$ não haja referência a critérios de elaboração, todas foram evidenciadas respeitando estrutura semelhante aos modelos regulamentados. Quanto à existência de não conformidade em relação a esses modelos, $23 \%$ do total apresentaram incongruências relacionadas à inclusão, detalhamento, classificação e estrutura de evidenciação de componentes da DVA. Como exemplo disso, citam-se a inclusão de contas tais como ajuste de exercícios anteriores e distribuição de dividendos oriundos de valor adicionado de exercício anterior na seção de distribuição do valor adicionado; a classificação de ganhos com venda de ativos como valor adicionado recebido em transferência; ou a classificação de despesa com constituição de provisão para contingência como retenção do valor adicionado bruto.

Sobre a submissão da informação produzida à auditoria externa, 17\% das DVA não foram referenciadas no parecer dos auditores, o que corresponde a 38 demonstrações, das quais 4 foram 
apresentadas taxativamente como informações não auditadas. Somado à elaboração com base em dados de outras demonstrações contábeis, o número expressivo de DVA auditadas confere maior credibilidade e verificabilidade aos dados divulgados e menor propensão a vieses.

A despeito de que a divulgação da DVA, segundo a NBC-T 3.7, não devesse se confundir com as notas explicativas, mas ser efetuada como informação complementar às demonstrações contábeis (CFC, 2005), 34\% das DVA se apresentaram em desacordo à orientação - 19\% foram divulgas no Relatório da Administração e 15\% em notas explicativas. $66 \%$ foram publicadas como informação suplementar no mesmo corpo de divulgação das demonstrações contábeis obrigatórias ou em anexo a estas. Menos de 1\% foi divulgado em outros relatórios tais como o relatório de sustentabilidade.

Na tabela 2, analisaram-se as diferenças entre os indicadores para as duas situações consideradas; observaram-se diferenças estatisticamente significantes para os indicadores VASR e RASVA. Tais achados indicam redução tanto do valor adicionado gerado em relação às vendas como da parcela destinada à remuneração de acionistas. Ainda, verifica-se que o decréscimo dos dois indicadores não se apresenta expressivamente relevante. A redução mais acentuada foi observada no comportamento do indicador RASVA, cuja média decresceu $17 \%$ comparativamente à redução de $9 \%$ da média do indicador VASR.

Tabela 2 - Comportamento dos Indicadores.

\begin{tabular}{cccccc}
\hline \multirow{2}{*}{ Indicadores } & \multicolumn{3}{c}{ Médias } & \multicolumn{2}{c}{ Estatísticas } \\
\cline { 2 - 6 } & $\begin{array}{c}\text { Divulgação } \\
\text { Obrigatória }\end{array}$ & $\begin{array}{c}\text { Divulgação } \\
\text { Voluntária }\end{array}$ & (Obrigatória - Voluntaria) & $\boldsymbol{t}$ & $\mathbf{Z}$ \\
\hline VASAT & 0,367 & 0,386 & $-0,019$ & 1,102 & $-1,037$ \\
VASPL & 1,157 & 1,267 & $-0,110$ & 1,191 & $-1,218$ \\
VASR & 0,503 & 0,552 & $-0,049$ & $2,449^{*}$ & $-3,527^{*}$ \\
PSVA & 0,222 & 0,223 & $-0,001$ & 0,047 & $-0,355$ \\
ISVA & 0,425 & 0,428 & $-0,003$ & 0,167 & $-0,348$ \\
RTSVA & 0,168 & 0,154 & 0,014 & $-1,201$ & 0,156 \\
RASVA & 0,079 & 0,095 & $-0,016$ & $2,393^{*}$ & $-2,581^{*}$ \\
LRSVA & 0,088 & 0,090 & $-0,002$ & 0,152 & $-0,531$ \\
\hline
\end{tabular}

Fonte: Dados da pesquisa. Notas: Processado por Testes de Diferenças de Médias (Paramétrico e Não Paramétrico). Onde: VASAT, Valor Adicionado sobre Ativo Total; VASPL, Valor Adicionado sobre Patrimônio Líquido; VASR, Valor Adicionado sobre Receita; PSVA, Pessoal sobre Valor Adicionado; ISVA, Impostos sobre Valor Adicionado; RTSVA. Remuneração de Terceiros sobre Valor Adicionado; RASVA, Remuneração de Acionistas sobre Valor Adicionado; LSVA, Lucros Retidos sobre Valor Adicionado. (*) Significante a 5\%.

$\mathrm{Na}$ tabela 3, onde se apresenta a análise por regressão logística, percebeu-se que se confirmaram os resultados da análise univariada, destacando-se que somente os indicadores VASR e RASVA se apresentaram significantes para a distinção entre os tratamentos de divulgação; tais resultados também se confirmaram pela aplicação do método stepwise (Backward - Llikelihood Ratio), não reportado.

Infere-se, de tal análise, dados os coeficientes negativos dos indicadores VASR e RASVA as alterações do marco regulatório contábil contribuíram para reduzir os montantes apurados e divulgados para os valores adicionados em relação às receitas, bem como se reduziu a parcela do valor adicionado reservado para os acionistas. 
Tabela 3 - Diferenciação dos Indicadores.

\begin{tabular}{ccc}
\hline Indicadores & Coeficientes & Expoentes \\
\hline VASAT & $-0,388$ & 0,679 \\
VASPL & $-0,058$ & 0,944 \\
VASR & $-1,099^{*}$ & 0,333 \\
PSVA & $-2,836$ & 0,059 \\
ISVA & $-1,872$ & 0,154 \\
RTSVA & $-1,585$ & 0,205 \\
RASVA & $-4,312^{*}$ & 0,013 \\
LSVA & $-1,510$ & 0,221 \\
\hline
\end{tabular}

Fonte: Dados da pesquisa. Notas: Processada por Regressão Logística (LOGIT). Onde: VASAT, Valor Adicionado sobre Ativo Total; VASPL, Valor Adicionado sobre Patrimônio Líquido; VASR, Valor Adicionado sobre Receita; PSVA, Pessoal sobre Valor Adicionado; ISVA, Impostos sobre Valor Adicionado; RTSVA. Remuneração de Terceiros sobre Valor Adicionado; RASVA, Remuneração de Acionistas sobre Valor Adicionado; LSVA, Lucros Retidos sobre Valor Adicionado. $\left(^{*}\right)$ Significante a $5 \%$

\section{CONCLUSÕES}

O estudo buscou verificar em que medida a determinação da obrigatoriedade de divulgação da DVA, instituída pela Lei $\mathrm{n}^{\mathrm{o}}$ 11.638/07, impactou os indicadores financeiros emanados da DVA de empresas brasileiras, alterando a qualidade informacional dos mesmos.

Estabeleceu-se como hipótese que não houve impactos nos indicadores emanados da DVA obrigatória ante os indicadores emanados da DVA voluntária, considerando que as condições de divulgação voluntária da DVA apresentavam-se, de certa forma, normatizados; de que as informações derivavam de relatórios contábeis previamente examinadas por auditoria independente, tendo sido expressamente auditadas a maioria das DVA.

Com base nos resultados, a hipótese de pesquisa foi aceita para 6 dos 8 indicadores em análise, podendo ser rejeitada apenas para os indicadores de geração de riqueza com base na receita e da parcela do valor adicionado reservada aos acionistas, que apresentaram diferenças estatisticamente significantes quando comparadas as observações originárias das duas formas de disclosure. Ainda, verificou-se que, após o marco regulatório, os indicadores impactados sofreram redução, mas que não se apresentou expressiva.

Os resultados, portanto, indicaram que o tratamento de divulgação obrigatória, no caso da DVA, apresentou baixo poder de determinação na diferenciação da qualidade de indicadores financeiros, fato que pode ser explicado pelas características da divulgação voluntária da DVA identificadas, como a submissão de mais de $80 \%$ das demonstrações aos procedimentos de auditoria independente; o uso de modelos consolidados pelas práticas contábeis e técnicas incentivadas por órgãos competentes, ainda que facultativos.

Deste ponto de vista, antes e após o processo regulatório, houve constatação de baixa incidência de não conformidade aos modelos de preparação da DVA, que não se apresentou comprometedora da finalidade precípua da DVA e pode estar associada à necessidade de maiores esclarecimentos sobre sua elaboração e divulgação. Ressalte-se ainda que os achados mostraram-se em desacordo com as afirmações de Tinoco (2009) sobre a sujeição da DVA voluntária a vieses que redundassem em informação pouco útil aos usuários.

Em vista disso, conclui-se que a obrigatoriedade da DVA, ainda que determinada junto às mudanças da contabilidade em convergência ao padrão IFRS - as quais poderiam ter levado à diferenciação das informações para os dois períodos analisados - não se manifestou como incentivo bastante para alterar a qualidade dos dados, o que contribui para a discussão sobre estabelecimento de obrigatoriedade para informações contábeis acessórias, sendo factível esperar que incentivos econômicos de demanda sejam eficientes quanto à divulgação de agregados e informações derivadas dos relatórios contábeis. 
Por fim, sugere-se para estudos futuros analisar a influência de tais alterações em decisões dos usuários da informação contábil, mormente de investidores e financiadores no mercado financeiro.

\section{REFERÊNCIAS}

ALENCAR, R. C. Nível de disclosure e custo de capital próprio no mercado brasileiro. 2007. Tese (Doutorado em Ciências Contábeis) - Faculdade de Economia, Administração e Contabilidade, Universidade de São Paulo, São Paulo, 2007.

BARBOSA, J. E. N.; DIAS, W. O.; MÁRIO, P. C. Regulação e sua influência no preço das ações: uma análise empírica no segmento da aviação civil. Revista de Contabilidade e Controladoria, Curitiba, v. 3, n. 1, p. 79-95, jan./abr. 2011.

BARBOSA, J. E. N.; DIAS, W. O.; PINHEIRO, L. E. T. Impacto da Convergência para as IFRS na Análise Financeira: um Estudo em Empresas Brasileiras de Capital Aberto. Revista Contabilidade Vista \& Revista, Belo Horizonte, v. 20, n. 4, p. 131-153, out./dez. 2009.

BRASIL. Lei № 11.638, de 28 de dezembro de 2007. Altera e revoga dispositivos da Lei № 6.404, de 15 de dezembro de 1976, e da Lei № 6.385, de 7 de dezembro de 1976, e estende às sociedades de grande porte disposições relativas à elaboração e divulgação de demonstrações financeiras. Diário Oficial [da] República Federativa do Brasil, Brasília, DF, 9 jan. 2008. Disponível em: http://www.planalto.gov.br/ccivil 03/ ato2007-2010/2007/lei/111638.htm. Acesso em: 8 set. 2013.

CARVAlHO, F. A.; PONTE, V. M. R.; COELHO, A. C. D.; DE LUCA, M. M. M. Impactos de alterações nas práticas contábeis nos indicadores financeiros das empresas brasileiras. In: CONGRESSO USP DE CONTROLADORIA E CONTABILIDADE, 11., 2011, São Paulo. Anais... São Paulo: FEA/USP, 2011.

COLAUTO, R. D.; MARQUES, V. A. Influência do discurso otimista do relatório de administração no valor de mercado de companhias brasileiras. Revista Contabilidade e Controladoria, Curitiba, v. 2, n. 1, p. 101-139, jan./abr. 2010.

CVM - COMISSÃO DE VALORES MOBILIÁRIOS. Deliberação CVM nº 557, de 12 de Novembro de 2008. Aprova o Pronunciamento Técnico CPC 09 do Comitê de Pronunciamentos Contábeis, que trata da Demonstração do Valor Adicionado. Disponível em:

http://www.cvm.gov.br/asp/cvmwww/atos/Atos/deli/deli557.doc. Acesso em: 11 set. 2013.

CVM - COMISSÃO DE VALORES MOBILIÁRIOS. Ofício-Circular CVM/SNC/SEP nํํ1, de 31 de janeiro de 2000. Encerramento do exercício social de 1999. Disponível em: < http://www.cvm.gov.br/port/atos/oficios/ofsnc-sep01-00.asp>. Acesso em: 8 set. 2013.

CFC - CONSELHO FEDERAL DE CONTABILIDADE. Resolução CFC nํ⒈010, de 21 de janeiro de 2005. Aprova a NBC T 3.7 - Demonstração do Valor Adicionado. Disponível em: http://www.cfc.org.br/sisweb/sre/detalhes sre.aspx?Codigo=2005/001010. Acesso em: 2 ago. 2014. 
CONSONI, S. Divulgação voluntária e sua relação com gerenciamento de resultados contábeis: Evidência no contexto da convergência às normais internacionaisde contabilidade no Brasil. 2014. Dissertação (Mestrado em Contabilidade) - Setor de Ciências Sociais Aplicadas, Universidade Federal do Paraná, Curitiba, 2014.

DIAS FILHO, J. M; CORRAR, L. Regressão Logística. In: CORRAR, L. J.; PAULO, E.; DIAS FILHO, J. M. (Coord.). Análise Multivariada: para os cursos de administração, ciências contábeis e economia. São Paulo: Atlas, 2009.

COSENZA, J. P. A eficácia informativa da Demonstração do Valor Adicionado. Revista Contabilidade e Finanças, São Paulo, ano 14, edição comemorativa, p. 7-29, 2003.

COSTA, R. A.; COSTA, F. M.; AMORIM, G.; BAPTISTA, E. C. S. O impacto da regulação no conservadorismo das empresas brasileiras listadas na BM\&FBOVESPA. Revista Contabilidade, Gestão e Governança, Brasília, v. 12, n. 3, p. 28-37, set./dez. 2009.

CRIPPA, M.; COELHO, A. C. D. Relevância e conteúdo informacional da Demonstração do Valor Adicionado: evidências para o Brasil. In: ANPCONT, 6., 2012, Florianópolis. Anais... Florianópolis: FURB, 2012.

CUNHA, J. V. A. Demonstração Contábil do Valor Adicionado - DVA: Um instrumento de mensuração da distribuição da riqueza das empresas para os funcionários. 2002. Dissertação (Mestrato em Controladoria e Contabilidade) - Faculdade de Economia, Administração e Contabilidade, Universidade de São Paulo, São Paulo, 2002.

CUNHA, J. V. A.; RIBEIRO, M. S. Divulgação voluntária de informações de natureza social: um estudo nas empresas brasileiras. In: ENANPAD, 30., 2006, Salvador. Anais... Salvador: ANPAD, 2006.

CUNHA, J. V. A.; RIBEIRO, M. S.; SANTOS, A. A Demonstração do Valor Adicionado como instrumento de mensuração da distribuição da riqueza. Revista Contabilidade e Finanças, São Paulo, n. 37, p. 7-23, jan./abr. 2005.

DE LUCA, M. M. M. Demonstração do Valor Adicionado. In: CONGRESSO BRASILEIRO DE CONTABILIDADE, 16., 1992, Salvador. Anais... Salvador: CFC, 1992.

DYE, R. A. An evaluation of "essays on disclosure" and the disclosure literature in accounting. Journal of Accounting and Economics, v. 32, p. 181-235, 2001.

ENTWISTLE, G. M. Managing disclosure: The case of research and development in knowledgebased firms. 1997. Tese (Doutorado em Filosofia) - Faculty of Graduate Studies. The University of Western Ontario, Canadá, 1997.

HUANG, H. Risk aversion, mandatory disclosure and the concealment of information. Economics Letters. Wellington, v. 99, n. 1, p. 2-9, out. 2007. Disponível em:

http://dx.doi.org/10.1016/j.econlet.2007.09.045. Acesso em: 30 maio 2013.

IUDÍCIBUS, S. et al. Manual de contabilidade societária. São Paulo: Atlas, 2010. 
KAIZER, C. V. C.; NOSSA, S. N.; TEIXEIRA, A. J. C.; BAPTISTA, E. C. S.; NOSSA, V. O impacto da regulamentação contábil sobre o conservadorismo nas empresas do setor elétrico do Brasil. Revista de Educação e Pesquisa em Contabilidade, Brasília, v. 3, n. 1, p. 1-24, jan./abr. 2009.

LOPES, A. B. A informação contábil e o mercado de capitais. São Paulo: Pioneira Thomson Learning, 2002.

LOPES, A. B.; TUKAMOTO, Y. S. Contribuição ao estudo do "gerenciamento" de resultados: uma comparação entre as companhias abertas brasileiras emissoras de ADRs e não-emissoras de ADRs. Revista de Administração da USP, São Paulo, v. 42, n. 1, p. 86-96, jan./mar. 2007.

MARTINS, O. S.; PAULO, E. Reflexo da adoção das IFRS na análise de desempenho das companhias de capital aberto no Brasil. Revista de Contabilidade e Organizações, São Paulo, v. 4, n. 9, p. 3054, maio/ago. 2010.

MURCIA, F. D. Interação entre Contabilidade e Direito: em busca de uma teoria da regulação contábil. Revista Catarinense da Ciência Contábil. Florianópolis, v. 9, n. 25, p. 19-32, dez./jan. 2010.

MURCIA, F. D.; SANTOS, A. Fatores determinantes do nível de disclosure voluntário das companhias abertas no Brasil. Revista de Educação e Pesquisa em Contabilidade, Brasília, v. 3, n. 2, p. 72-95, maio/ago. 2009.

PAULO, E. Manipulação das informações contábeis: Uma análise teórica e empírica sobre os modelos operacionais de detecção de gerenciamento de resultados. 2007. Tese (Doutorado em Ciências Contábeis) - Faculdade de Economia, Administração e Contabilidade, Universidade de São Paulo, São Paulo, 2007.

POPOVA, T.; GEORGAKOPOULOS, G.; SOTIROPOULOS, I.; VASILEIOU, K. Z. Mandatory disclosure and its impact on the company value. International Business Research. Toronto, v. 6, n. 5, abr. 2013. Disponível em: http://dx.doi.org/10.5539/ibr.v6n5p1. Acesso em: 12 ago. 2013.

SALOTTI, B. M.; YAMAMOTO, M. M. Divulgação voluntária da Demonstração dos Fluxos de Caixa no mercado de capitais brasileiro. Revista Contabilidade e Finanças, São Paulo, v. 19, n. 48, p. 37-49, set./dez. 2008.

SANTOS, A. Demonstração do Valor Adicionado: como elaborar e analisar a DVA. 2. ed. São Paulo: Atlas, 2007.

SARLO NETO, A.; LOPES, A. B.; LOSS, L. O impacto da regulamentação sobre a relação entre lucro e retorno das ações das empresas dos setores elétrico e financeiro no Brasil. In: ENANPAD, 26., 2002, Salvador. Anais... Salvador: ANPAD, 2002.

TINOCO, João Eduardo Prudêncio. Balanço Social: uma abordagem de transparência e da responsabilidade pública das organizações. São Paulo: Atlas, 2009. Reimpressão.

VERRECCHIA, R. E. Essays on disclosure. Journal of Accounting and Economics, v. 32, n. 1, p. 97-180, 2001. 
YAMAMOTO, M. M.; SALOTTI, B. M. Informação contábil: estudos sobre a sua divulgação no mercado de capitais. São Paulo: Atlas, 2006. 